\title{
The effect of the austenite grain refinement on the tensile and impact properties of cast Hadfield steel
}

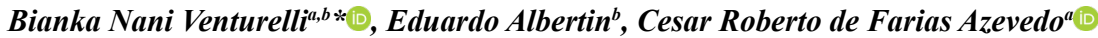 \\ ${ }^{a}$ Departmento de Engenharia Metalúrgica e de Materiais, Escola Politécnica, Universidade de São \\ Paulo - USP, Av. Professor Mello Moraes, 2463, CEP 05508-030, São Paulo, SP, Brasil \\ ${ }^{b}$ Instituto de Pesquisas Tecnológicas do Estado de São Paulo - IPT, Av. Prof. Almeida Prado, 532, CEP \\ 05508-901, São Paulo, SP, Brasil
}

Received: January 27, 2018; Revised: May 30, 2018; Accepted: June 25, 2018

\begin{abstract}
This paper studied the effect of the austenite grain refinement on the tensile and impact properties of a cast Hadfield steel $(12 \% \mathrm{Mn}, 1.2 \% \mathrm{C}$ and $0.65 \% \mathrm{Si})$. The austenite grain refinement was obtained by hafnium inoculation. Microstructural characterization showed that the Hf-refined cast Hadfield steel featured a grain size of $600 \mu \mathrm{m}$, while the non-refined condition presented a grain size of $3000 \mu \mathrm{m}$. Mechanical test results indicated that the austenite grain refinement promoted an increase in the values of the yield stress $(6 \%)$, the ultimate tensile strength $(37 \%)$, the toughness $(88 \%)$, the work-hardening coefficient (50\%) and the Charpy absorbed energy (15\%). Microscopic characterization of the fractured test-pieces indicated that the grain refinement increased the proportion of plastic deformation by the twinning mechanism and furthermore improved the values of the mechanical properties of the cast Hadfield steel considerably.
\end{abstract}

Keywords: cast Hadfield steel, austenite grain refinement, hafnium inoculation, mechanical properties, plastic deformation mechanisms, mechanical twinning.

\section{Introduction}

Hadfield steel (1.2 wt. \% C and 12.5 wt. \% Mn) was patented in 1882 by Sir Abbot Hadfield and its many grades feature a relevant association of high values of toughness (impact energy between 110 and $180 \mathrm{~J} / \mathrm{cm}^{2}$ ) and strainhardening exponent $(0.45 \text { to } 0.95)^{1-4}$. Therefore, the family of the Hadfield steels has been widely used in applications involving high impact, compressive stress and abrasive wear $^{4-7}$. The slow cooling rate during the casting process of the Hadfield steel promotes the precipitation of carbides along the austenite grain boundaries and a solution heat-treatment at temperatures between 950 and $1500^{\circ} \mathrm{C}$ is necessary in order to obtain a fully austenitic microstructure at room temperature ${ }^{8}$. Optimization of the wear properties and toughness of the Hadfield steels by microstructural design is a key stage to increase the service life of critical engineering components of the mining industry ${ }^{1-7}$.

The effect of the grain refinement on the yield stress of metallic materials has been described by the Hall-Petch equation, but the effectiveness of this refinement on the yield stress strongly depends on the value of the Hall-Petch coefficient $^{9-10}$. Additionally, FCC metals are known to feature low values for this coefficient, suggesting that the austenite grain refinement might not be very effective to increase the yield stress of the Hadfield steel. However, the Hadfield steels show intermediate values for the stackingfault energy ( 20 to $40 \mathrm{~mJ} / \mathrm{m}^{2}$ ), which promotes the plastic

*e-mail: bianka_venturelli@hotmail.com deformation by the twinning mechanism (see Figure 1), using the $\{111\}<11-2>$ twinning system of the austenite ${ }^{11-13}$. The synergetic action of the twinning and slip mechanisms during the plastic deformation might increase the values of the work-hardening coefficient and the toughness of the Hadfield and TWIP (twinning-induced plasticity) steels ${ }^{11-16}$.

Adler, Olson and Owen ${ }^{17}$ examined the stress-strain response of a wrought Hadfield steel (austenite grain size of $50 \mu \mathrm{m}$ ) during tensile and compression testing. The results showed a higher value of the strain-hardening exponent during

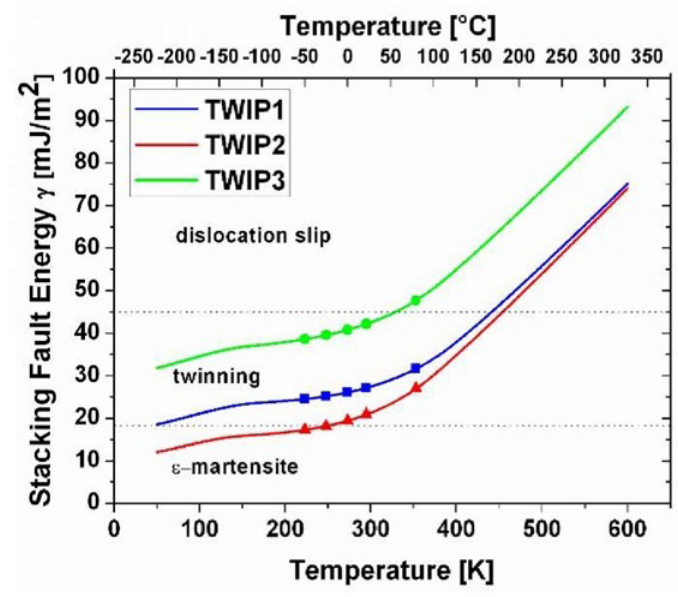

Figure 1. The stacking fault energy $(\gamma)$ of the TWIP steels as a function of temperature and plastic deformation mechanism. The graph features the domain fields for each one of the plastic deformation mechanisms of the austenite, including the formation of $\varepsilon$-martensite ${ }^{14}$. 
the compression testing, which was explained by the higher proportion of plastic deformation by twinning. Bayraktar et a ${ }^{18}$ studied the effects of the tensile testing temperature and strain rate on the deformation and fracture behaviour of a wrought high Mn steel. They observed that the proportion of plastic deformation by twinning increased progressively with the increase of the strain rate. They also detected that the hardness of the twinned regions $(600 \mathrm{HV})$ was much higher than the areas without the presence of mechanical twins (350 HV). They finally observed that the plastic deformation by twinning was promoted at low temperatures and/or high strain rates. In 2013, Yeleussizova et al ${ }^{19}$ studied the deformation by twinning of Hadfield steels using tensile testing at room temperature. Their results showed that the contribution of the twinning mechanism to the total plastic deformation was around $33 \%$ of the overall plastic deformation, indicating a simultaneous action of the slip and twinning mechanisms. The authors ${ }^{19}$ affirmed, however, that the higher proportion of plastic deformation by mechanical twinning reduced the strain-hardening coefficient of the Hadfield steels. This brief literature survey ${ }^{11-19}$ shows that there is an ongoing dispute over the role of the stacking fault energy of austenite on the mechanisms of plastic deformation (mechanical twinning versus slip). Additionally, it also demonstrates the need to understand how the interaction between slip and mechanical twinning might affect the values of the toughness and strainhardening exponent of Hadfield and TWIP steels.

Haakonsen ${ }^{20}$ studied the refinement of the austenite grain size of a cast Hadfield steel with addition of Ce (0-0.05\%). His results showed a decrease of the austenite grain size from $570 \mu \mathrm{m}$ to $210 \mu \mathrm{m}$ with the addition of $0.05 \%$ of Ce, but these results were restricted only to a thin surface layer of the casting ${ }^{20}$. The use of hafnium as austenite grain refiner of cast Hadfield steels was briefly described for the first time in a European patent in $2012^{21}$, which also indirectly presented in a table the effect of the refinement on the mechanical properties of the cast Hadfield steels.

The present study will assess the effect of the austenite grain refinement obtained by Hf-inoculation on the tensile and impact properties of a cast Hadfield steel. The microscopic characterization of the fractured test-pieces will investigate how the austenite grain refinement affects the dispute between the slip and twinning mechanisms during the plastic deformation of cast Hadfield steel.

\section{Materials and Methods}

ASTM A128 standard (grade B2) cast Hadfield steels were prepared in an induction furnace. The addition of $\mathrm{Hf}$ in the liquid steel was used as an inoculant in order to promote the austenite grain refinement ${ }^{22}$ and keel blocks were cast using a pouring temperature of $1450^{\circ} \mathrm{C}$. Table 1 shows the chemical composition of the Hadfield steel castings, which are in accordance with ASTM A128 standard (grade B2).
The chemical analysis of $\mathrm{Si}, \mathrm{Mn}$, and $\mathrm{P}$ was determined by X-ray fluorescence spectroscopy technique, using a Shimadzu XRF 1500 spectrometer. The determination of $\mathrm{C}$ and $\mathrm{S}$ contents was obtained by the direct combustion method, using a LECO CS 300.

The castings were solution heat-treated at $1100^{\circ} \mathrm{C}$ for 10 hours and quenched in water. Metallographic samples were etched in Nital $3 \%$ and the measurements of the austenitic grain size followed the guidelines of the ASTM-E112 standard. The specimens for the tensile and the V-notched Charpy impact testing were cut and prepared by electrical discharge machining (EDM), with geometry and dimensions given by ASTM-E8M and ASTM-E23 standards, respectively. The tensile tests were performed on a MTS Sintech machine at room temperature $\left(23^{\circ} \mathrm{C}\right)$, using a strain rate of $10^{-6} \mathrm{~s}^{-1}$, while the Charpy impact tests were performed on a Wolpert PW 30/15 machine at room temperature $\left(23^{\circ} \mathrm{C}\right)$, using a load of $294 \mathrm{~J}$.

The fracture surfaces of tensile and Charpy specimens were examined using a Jeol JSM 6300 scanning electron microscope, while the microstructural characterization of the regions near their fracture surfaces was carried out using optical and scanning microscope, and EBSD (electron backscattering diffraction) imaging.

\section{Results}

\subsection{Microstructural characterization of the solution heat-treated specimens of cast Hadfield steel with different austenitic grain sizes}

The macrostructure of the non-refined cast Hadfield steel featured three distinct zones in the as-cast condition: the outer chill zone (length of $2 \mu \mathrm{m}$ ), the columnar zone (length of $15 \mu \mathrm{m}$ ) and the central equiaxed zone (length of $30 \mu \mathrm{m}$ ). These macrostructural features were also observed after the solution heat-treatment, indicating the absence of austenite grain growth during this heat-treatment. The average austenitic grain size in the columnar zone along the direction of the preferential grain growth was $4000 \mu \mathrm{m}$ (see Figure 2-a), while the average austenitic grain size in the equiaxed zone was around $3000 \mu \mathrm{m}$ (see Figure 3-a). Additionally, the EBSD image of the equiaxed zone (see Figure 3-a) shows areas with small crystallographic misorientation inside a single

Table 1. Chemical composition of the Hf-refined and non-refined cast Hadfield steels.

\begin{tabular}{lccccc}
\hline & $\% \mathrm{C}$ & $\% \mathrm{Mn}$ & $\% \mathrm{Si}$ & $\% \mathrm{P}$ & $\% \mathrm{~S}$ \\
\hline $\begin{array}{l}\text { ASTM A128- B2 } \\
\text { Non-refined }\end{array}$ & $1.05-1.2$ & $11.5-14$ & $<1$ & - & - \\
$\begin{array}{l}\text { Hadfield steel } \\
\begin{array}{l}\text { Hf-refined } \\
\text { Hadfield steel }\end{array}\end{array}$ & 1.23 & 11.98 & 0.64 & 0.034 & 0.037 \\
\hline
\end{tabular}




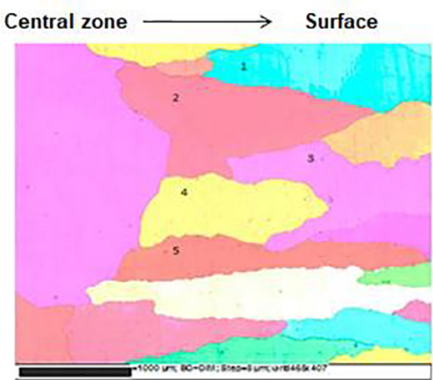

(a)

Figure 2. EBSD analysis of the columnar zone of the non-refined cast Hadfield steel. (a) EBSD map; (b) Inverse pole figure, indicating the crystallographic orientations of the austenitic columnar grains marked in (a).

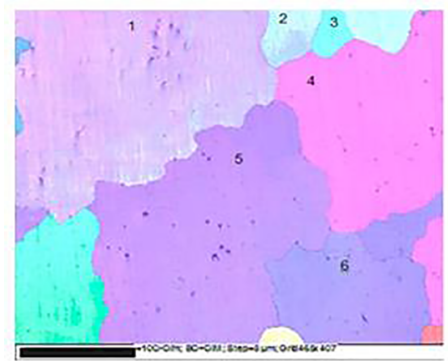

(a) (b)

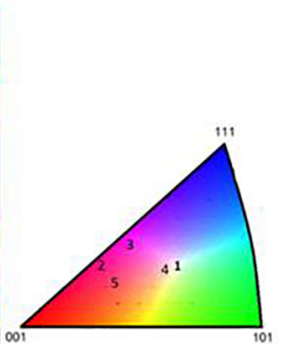

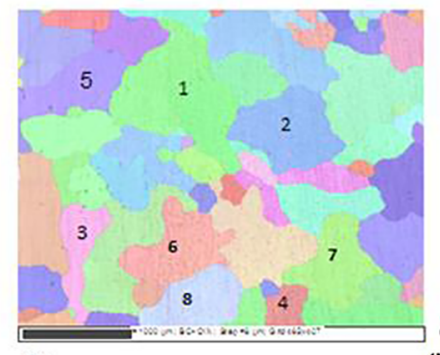

(a)

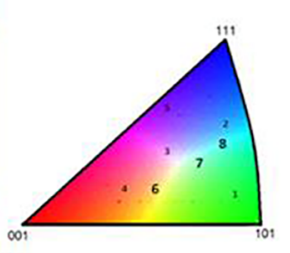

(b)

Figure 4. EBSD analysis of the equiaxed zone of the Hf-refined cast Hadfield steel. (a) EBSD map; (b) Inverse pole figure, indicating he crystallographic orientations of the austenitic columnar grains marked in (a).

non-refined condition. By contrast, the values of the strainhardening exponent, ductility, tensile strength and toughness featured a much higher increase (between 40 and $90 \%$ ) in comparison with the non-refined condition. Additionally, the value of the Charpy absorbed energy of the Hf-refined condition $\left(176 \mathrm{~J} / \mathrm{cm}^{2}\right)$ was $13 \%$ higher than the non-refined condition $\left(156 \mathrm{~J} / \mathrm{cm}^{2}\right)$.

An extrapolation of the yield strength value produced by austenite grain refinement was obtained using the HallPetch equation and the following parameters: Hall-Petch coefficient $\left(\mathrm{KHP}=0.452 \mathrm{MPa} \cdot \mathrm{m}^{1 / 2}\right)$ and friction stress $\left(\sigma_{0}=\right.$ $318 \mathrm{MPa})^{24}$. This result indicated an increase of $12.5 \%$ in the yield strength of the cast Hadfield steel when the austenite grain size was reduced from $3000 \mu \mathrm{m}$ to $600 \mu \mathrm{m}$, which is in good agreement with the experimental result (see Table 2). The Hall-Petch law, however, cannot explain the much higher increase in the values of the strain-hardening exponent, ductility, tensile strength and toughness observed for the refined condition. These experimental values suggest that the austenite grain refinement caused a change in the role of slip and mechanical twinning during the plastic deformation of the cast Hadfield steel ${ }^{11-19}$. merely showed the presence of equiaxed zone, indicating that the Hf-inoculation produced a more "homogeneous" distribution of the heterogeneous nucleation sites for the solidification of austenite. The average austenitic grain size was $600 \mu \mathrm{m}$ (see Figure 4-a) and this condition apparently did not show the presence of subgrains. Additionally, the inverse pole Figure (see Figure 4-b) indicates that the austenite grains show a more random crystallographic orientation than the equiaxed region of the non-refined condition (see Figure 3-b). Finally, Hf-inoculation promoted the microstructural refinement of the austenitic grain of the cast Hadfield steel by a factor of five (see Figures 3-a and 4-a).

\subsection{Mechanical test results}

Table 2 shows the results of the tensile tests. The values of the yield strength and the resilience of the Hf-refined steel featured a small increase $(<10 \%)$ in comparison with the

Table 2. Effect of the grain refinement on the tensile properties of the cast Hadfield steel.

\begin{tabular}{lccc}
\hline $\begin{array}{l}\text { Mechanical } \\
\text { properties }\end{array}$ & $\begin{array}{c}\text { Non- } \\
\text { refined cast } \\
\text { Hadfield } \\
\text { steel }\end{array}$ & $\begin{array}{c}\text { Hf-refined } \\
\text { cast } \\
\text { Hadfield } \\
\text { steel }\end{array}$ & $\begin{array}{c}\text { Increase in } \\
\text { values (\%) }\end{array}$ \\
\hline $\begin{array}{l}\text { Yield strength } \\
\text { (MPa) }\end{array}$ & $334 \pm 3$ & $355 \pm 2$ & $\uparrow 6$ \\
$\begin{array}{l}\text { Resilience (J) } \\
\begin{array}{l}\text { Strain-hardening } \\
\text { exponent }\end{array}\end{array}$ & $282 \pm 4$ & $304 \pm 4$ & $\uparrow 8$ \\
$\begin{array}{l}\text { Ductility (\%) } \\
\text { Tensile strength } \\
\text { (MPa) }\end{array}$ & $47 \pm 1$ & $71 \pm 1$ & $\uparrow 53$ \\
Toughness (J) & $409 \pm 3$ & $771 \pm 3$ & $\uparrow 88$ \\
\hline
\end{tabular}




\subsection{Microfractographic examination}

The microfractographic aspects of the ruptured tensile test pieces are shown in Figures 5 to 8. The fracture surfaces of the non-refined cast steel (Figures 5 and 6) showed regions with ductile fracture by dimples (slip mechanism, see Figure 5 ), featuring two different diameters for the dimples (around $10 \mu \mathrm{m}$ and $2 \mu \mathrm{m}$ ), and flat regions with the presence of parallel lines (see Figure 6), resembling the activation of the twinning mechanism ${ }^{24}$. The total length of the twins is close to $850 \mu \mathrm{m}$, suggesting that the twinning mechanism took place inside the subgrains of the non-refined condition (see Figure 3-a).

The fracture surfaces of the Hf-refined cast steel (Figures 7 and 8) showed regions with ductile fracture by dimples (see Figure 7), with diameter between 1 and $3 \mu \mathrm{m}$, and regions with ductile fracture by twinning (the length of the twins is close to $200 \mu \mathrm{m}$, see Figure 8), indicating that the twinning mechanism took place inside the subgrains of the refined condition (see Figure 4-a).

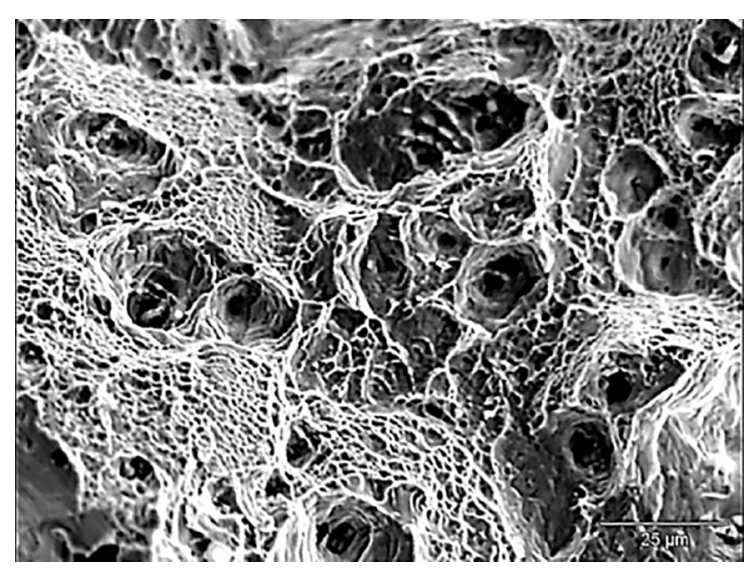

Figure 5. Microfractographic examination of the non-refined Hadfield steel after the tensile testing, featuring ductile fracture with the presence of dimples, SEM, SEI.

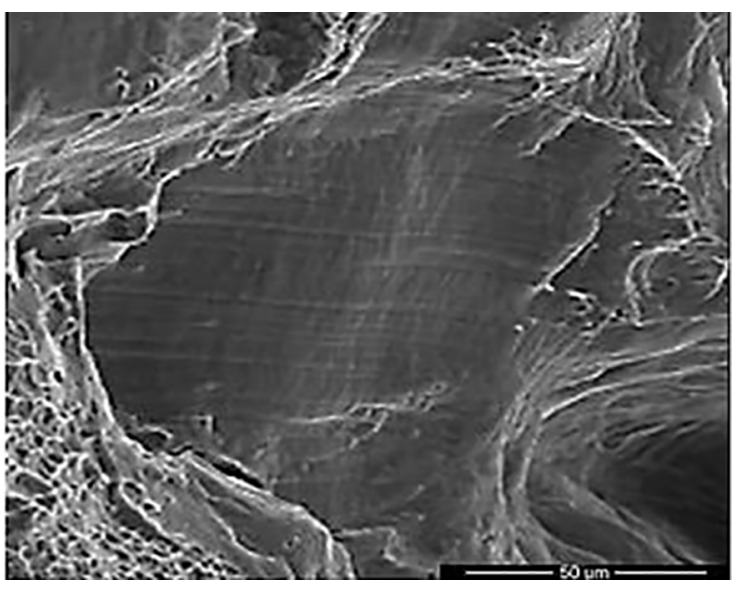

Figure 6. Microfractographic examination of the non-refined cast Hadfield steel after tensile testing, featuring ductile fracture by twinning, SEM, SEI.

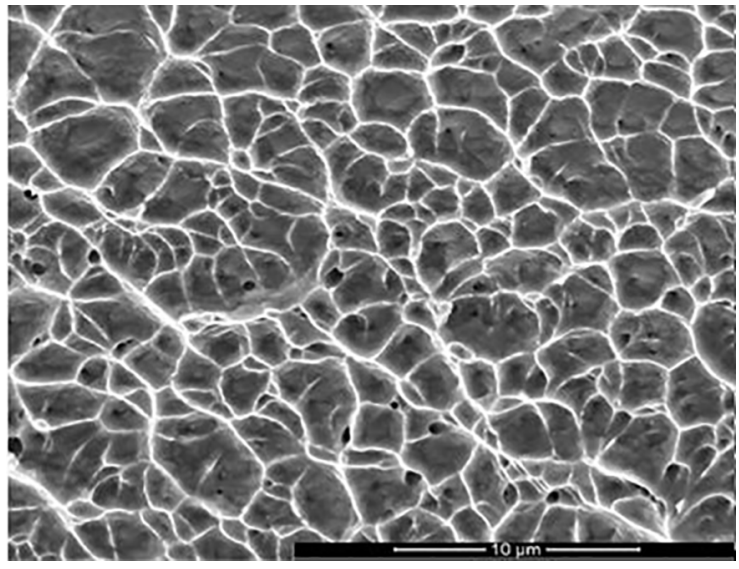

Figure 7. Microfractographic examination of the Hf-refined cast Hadfield steel after tensile testing, featuring ductile fracture with the presence of dimples, SEM, SEI.

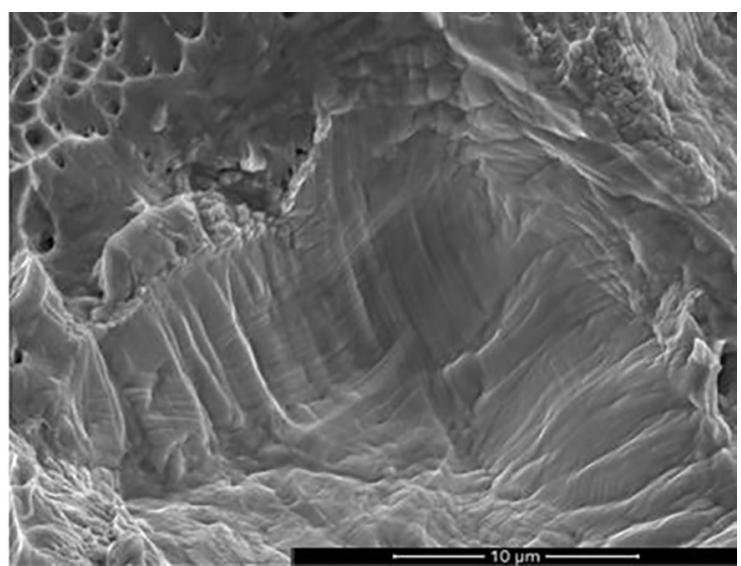

Figure 8. Microfractographic examination of the Hf-refined cast Hadfield steel after tensile testing, featuring ductile fracture with the presence of mechanical twins, SEM, SEI

The microfractographic results of the Charpy tests are shown in Figures 9 to 12 . The fracture surface of the nonrefined cast Hadfield steel showed regions with the presence of mechanical twins (length of approximately $500 \mu \mathrm{m}$, see Figure 9), confirming that the twinning mechanism took place inside the subgrains (see Figure 3-a). Additionally, the characterization indicated the presence of many regions with fracture by dimples (diameter between 1 and $3 \mu \mathrm{m}$, see Figure 10). These results confirmed that the fracture of nonrefined Hadfield cast steel during the Charpy test occurred by a ductile mechanism.

The fracture surfaces of the Hf-refined cast Hadfield steel (see Figures 11 and 12) showed regions with ductile fracture by dimples (see Figure 11) and regions with ductile fracture by twinning (the length of the twins is approximately $50 \mu \mathrm{m}$, see Figure 12), indicating that the twinning mechanism took place inside the subgrains (see Figure 4-a).

The microfractographies of the tensile and impact test pieces of the Hf-refined cast Hadfield steel apparently showed 


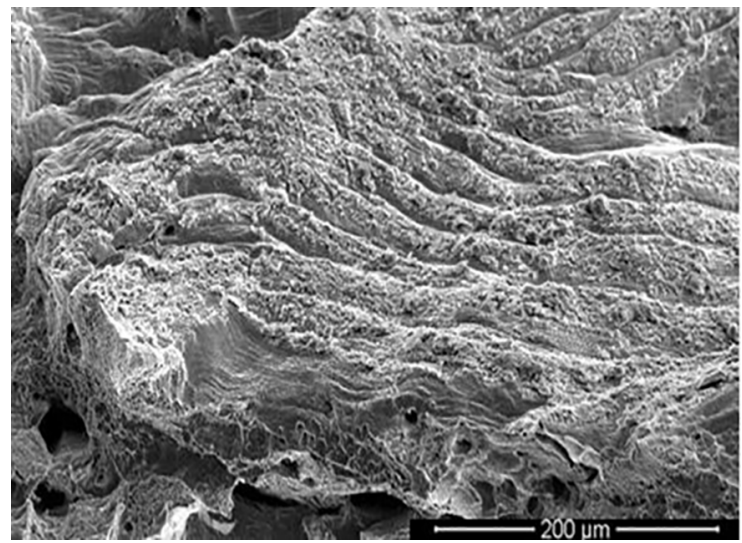

Figure 9. Ductile fracture of the non-refined cast Hadfield steel after impact testing, showing the presence of deformation twins, SEM, SEI.

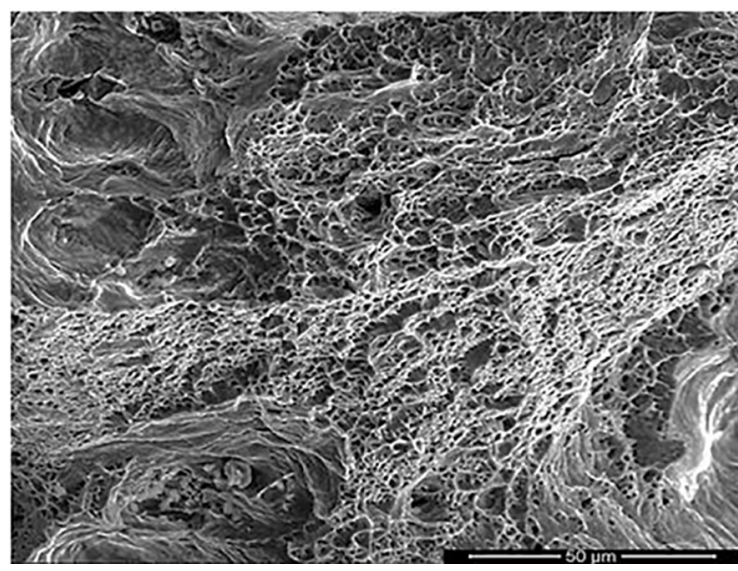

Figure 10. Ductile fracture of the non-refined cast Hadfield steel after impact testing, showing the presence of dimples, SEM, SEI.

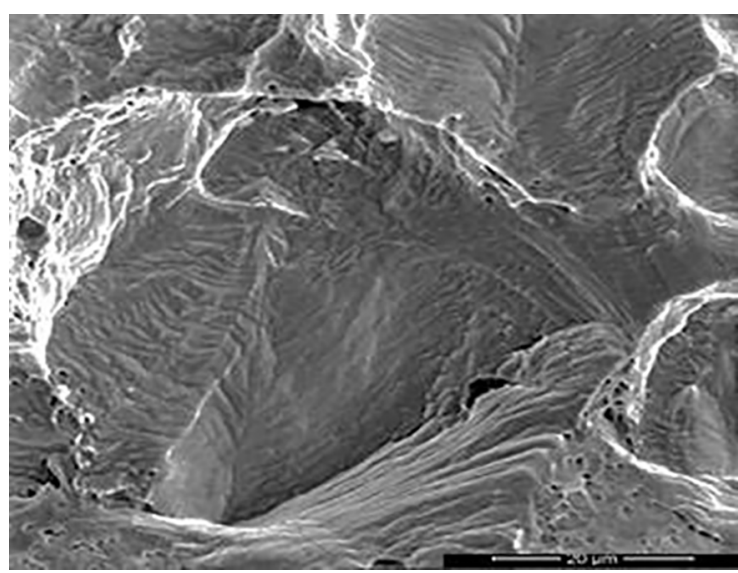

Figure 11. Ductile fracture of the Hf-refined cast Hadfield steel after impact testing, featuring the presence of mechanical twins. SEM, SEI.

a higher proportion of areas with the presence of mechanical twins than the non-refined cast Hadfield steel.

\subsection{Microscopic observation of mechanical twins}

Figures 13-a and 13-b show the microstructure of the transversal cross-sections adjacent to the fracture surfaces of the tensile specimens. The presence of mechanical twins was observed in the refined and non-refined conditions. The non-refined cast Hadfield steel shows mechanical twins, whose maximum length was approximately $800 \mu \mathrm{m}$, while the maximum length of the mechanical twins of the Hfrefined cast Hadfield steel was around $300 \mu \mathrm{m}$. The value of the density of mechanical twinning was $46 \%$ higher in Hf-refined steel ( $35 \pm 5$ twins per $\mu \mathrm{m})$ in comparison with the non-refined steel $(19 \pm 4$ twins per $\mu \mathrm{m})$, indicating that the austenite grain refinement of the cast Hadfield steel increased the proportion of plastic deformation by mechanical twinning during the tensile testing.

Figures 14 and 15 show the microstructure of the transversal cross-sections adjacent to the fracture surfaces of the impact specimens. The presence of mechanical twins was observed for both steels, but once again the density of the mechanical twinning was $43 \%$ higher in the Hf-refined cast Hadfield steel (42 \pm 6 twins per $\mu \mathrm{m}$, see Figures 15 -a and 15-b) in comparison with the non-refined cast Hadfield steel ( $24 \pm 4$ twins per $\mu \mathrm{m}$, see Figures 14 -a and 14-b). These results indicate that the austenite grain refinement of the cast Hadfield steel increased the proportion of plastic deformation by mechanical twinning during the Charpy testing.

\section{Discussion}

The tensile test results showed that austenite grain refinement of the Hadfield steel promoted an increase on yield stress $(6 \%)$, resilience $(8 \%)$, tensile strength (37\%), ductility (53\%), toughness ( $88 \%$ ), strain-hardening exponent (50\%) and Charpy impact energy (13\%). The small increase on the yield stress $(6 \%)$ caused by the austenite grain refinement (from 3000 to $600 \mu \mathrm{m}$ ) of the cast Hadfield steel

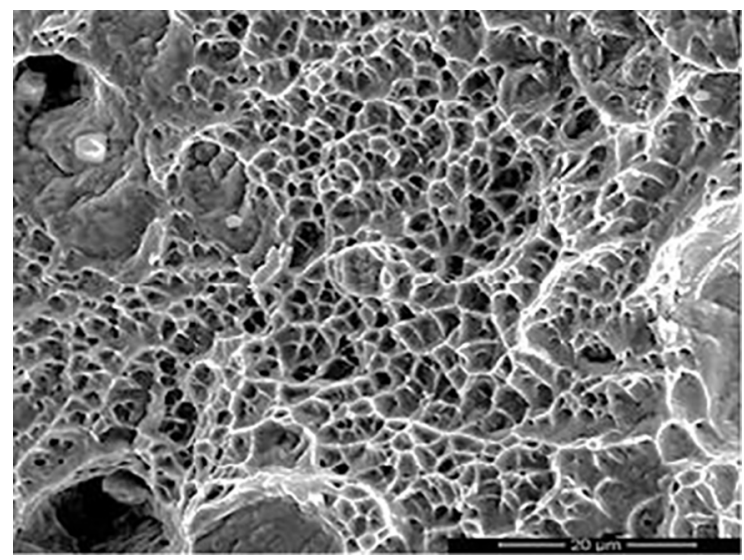

Figure 12. Ductile fracture of the Hf-refined cast Hadfield steel after impact testing, featuring the presence of dimples, SEM, SEI. 


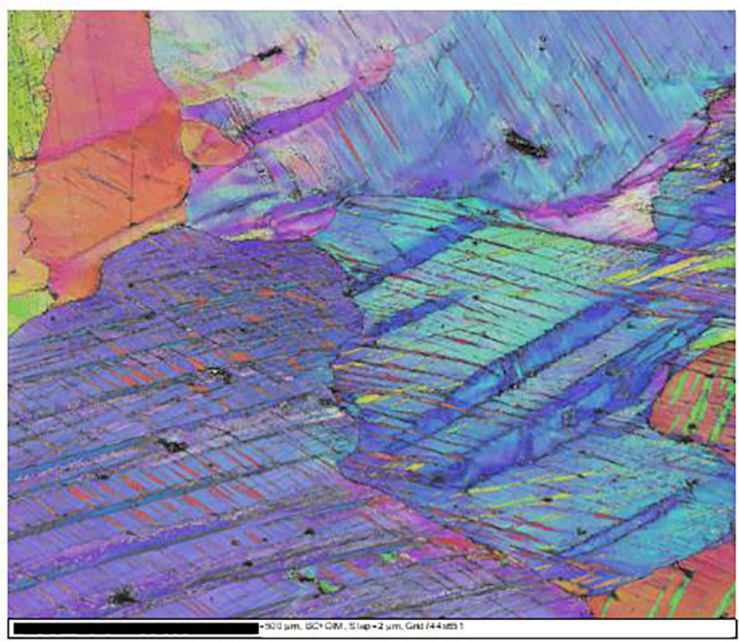

(a)

Figure 13. EBSD image of the transversal section adjacent to the surface of the tensile specimens showing the presence of mechanical twins: (a) Non-refined cast Hadfield steel and; (b) Hf-refined cast Hadfield steel.

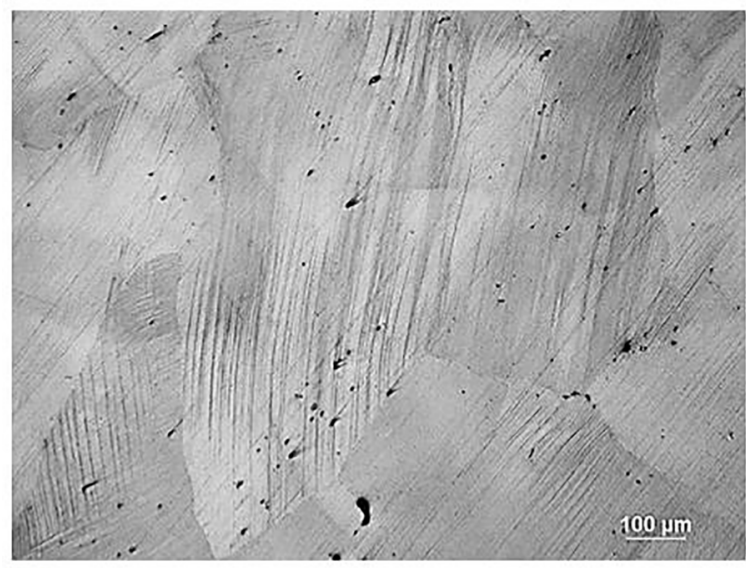

(a)

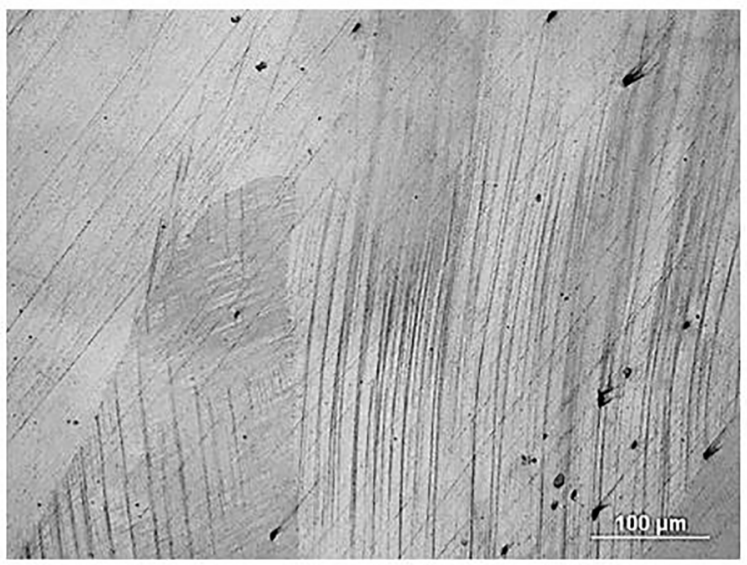

(b)

Figure 14. Microstructural characterization of the transversal section adjacent to the fracture surface of the impact specimens of the nonrefined cast Hadfield steel. (a) and (b) Mechanical twins. Optical microscopy.

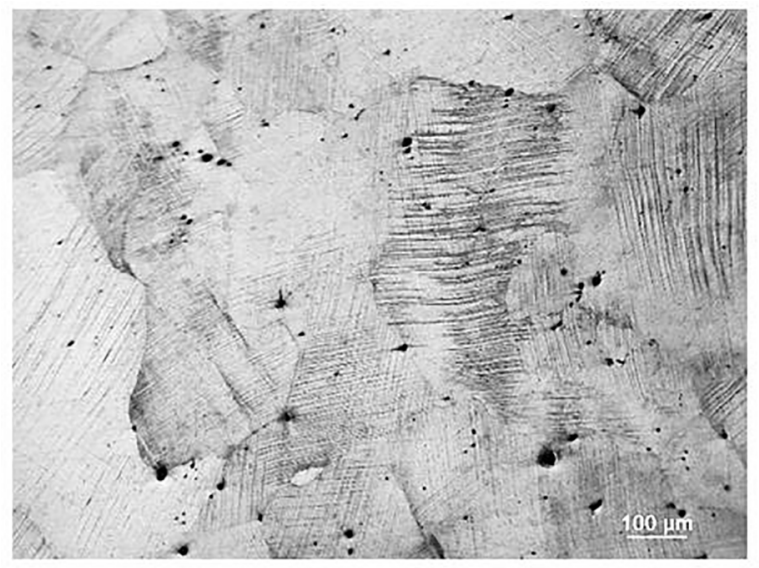

(a)

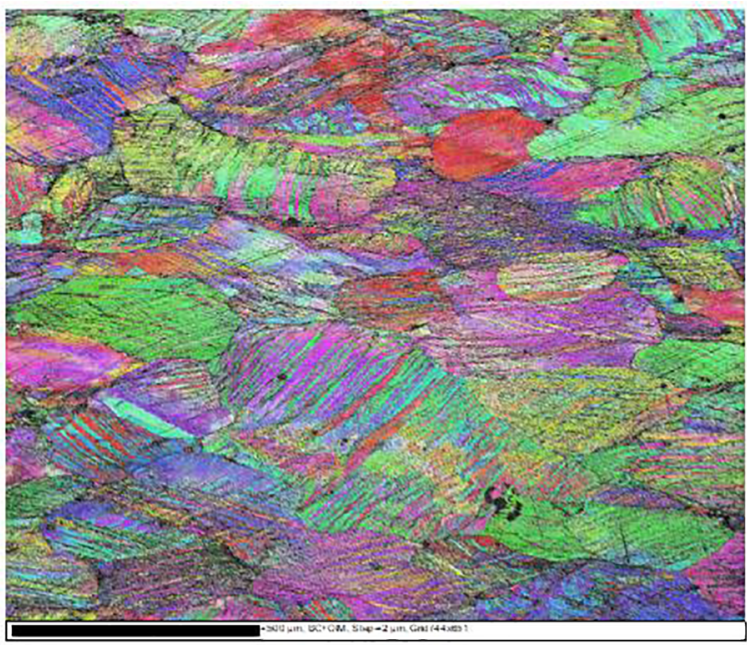

(b) 
is in agreement with the Hall-Petch's Law for austenitic steels (FCC), which feature a low value for the Hall-Petch coefficient $\left(0.3-0.7 \mathrm{MPa} \cdot \mathrm{m}^{1 / 2}\right)^{9,10,23}$.

The increase in the values of the tensile strength, strainhardening coefficient, ductility, toughness and Charpy impact energy with the reduction of austenite grain size (see Table 2) could not be explained by the Hall-Petch's law, indicating that the refinement of the austenite grain size of the cast Hadfield steel promoted a change in the mechanism of plastic deformation ${ }^{9-19,22-23,25}$.

Karaman ${ }^{25}$ studied the stress-strain response of wrought Hadfield steel $(12.3 \% \mathrm{Mn}$ and $1.03 \% \mathrm{C})$ with different austenite grain sizes $(100,300$ and $1000 \mu \mathrm{m})$ in order to verify the effect of grain size on the mechanical properties. The tensile test results obtained in the present study fit well with Karaman's results ${ }^{25}$, see Figure 16 . The values of the tensile strength in the present study (689 MPa for the nonrefined and $930 \mathrm{MPa}$ for the Hf-refined cast Hadfield steel) are, however, much higher than the values obtained by Karaman (around $580 \mathrm{MPa}$ for the wrought Hadfield steel with $1000 \mu \mathrm{m}$ and $660 \mathrm{MPa}$ for the grain size of $300 \mu \mathrm{m}$ ). Additionally, the current work also showed much higher values for the elongation, signifying the good quality of the present casting procedure.

Fractographic and microstructural characterization (see Figures 5 to 15) showed the presence of mechanical twins after the tensile and Charpy impact testing for both nonrefined and Hf-refined conditions. The twins' density of the Hf-refined condition was $46 \%$ higher in comparison with the non-refined condition, indicating that the plastic deformation by twinning (induced by austenite grain refinement) played a significant role in the improvement of the tensile and impact properties of the cast Hadfield steel. In the literature ${ }^{11-19,25}$, however, there is no consensus regarding the effect of the

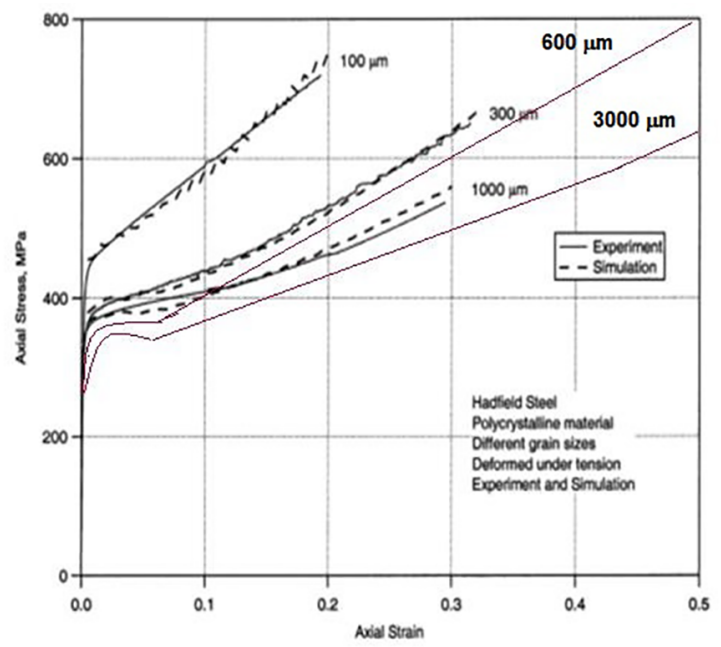

Figure 16. The stress-strain response of a wrought Hadfield steel $(12.3 \% \mathrm{Mn}$ and $1.03 \% \mathrm{C})$ with grain size of 100,300 e $1000 \mu \mathrm{m}$ (25). The graph also shows the present results for cast Hadfield steel featuring grain sizes of $3000 \mu \mathrm{m}$ e $600 \mu \mathrm{m}$. plastic deformation by twinning on the mechanical properties of the Hadfield steels.

Qin and Badeshia ${ }^{26}$ studied the effect of mechanical twinning on the plastic deformation of TWIP steel $(25 \%$ $\mathrm{Mn}, 3 \% \mathrm{Si}$ and $3 \% \mathrm{Al}$ ), featuring high values of elongation (60 - $95 \%$ ). According to the authors, the plastic deformation by twinning is an important mechanism for the improvement of the mechanical properties of TWIP steels, but it does not contribute significantly to their high values of elongation. The present work indicated, however, that the austenite grain refinement promoted an increase of $46 \%$ in the density of twins and $53 \%$ in the elongation values, suggesting that the higher proportion of mechanical twinning increased the ductility of cast Hadfield steel.

According to the literature ${ }^{11-15}$, the value of the stacking fault energy of the Fe-C-Mn alloys is, indeed, of vital importance for the activation of the mechanical twinning in the austenite (see Figure 1), as the cross-slip becomes more difficult for lower and intermediate values of SFE. The investigated cast Hadfield steels presents a SFE value around $40 \mathrm{~mJ} / \mathrm{m}^{2} 11-15$, which is in accordance with the observed values for the activation of the mechanical twinning during plastic deformation. The activation of twinning possibly takes place after the pile-up of the dislocations during the strain hardening of austenitic steels featuring low values of SFE values. Additionally, the twin boundaries act as extra barriers to the dislocation slip, showing the complex interactions between slip and twinning 11-19,22,25-26.

The most interesting result of the present investigation is that the austenite grain refinement of the cast Hadfield steel increased the contribution of the twinning mechanism to the plastic deformation, improving considerably the tensile strength, ductility, toughness, strain-hardening exponent and Charpy impact energy. Karaman ${ }^{25}$, nevertheless, showed that the coarse-grained wrought Hadfield steels are predominantly deformed by mechanical twinning, while the refined Hadfield steels are deformed by slip and twinning mechanisms. Finally, Karaman ${ }^{25}$ showed that the austenite grain refinement increases the strain-hardening exponent, which is in agreement with the present result. Further investigation is needed to understand how the austenite grain size influences the onset of the mechanical twinning during the plastic deformation and how to optimize the mechanical properties of Hadfield and TWIP steels via microestrutural design.

\section{Conclusions}

1. Microstructural characterization showed that the austenite grain size of the cast Hadfield steel inoculated with $\mathrm{Hf}$ is five times smaller $(600 \mu \mathrm{m}$ versus $3000 \mu \mathrm{m})$ than the non-refined cast Hadfield steel;

2. Tensile test results indicated that the reduction of the austenite grain size of the cast Hadfield steel 
caused a small increase of the yield strength (6\%), which is in agreement with the Hall-Petch law;

3. The reduction of the austenite grain size of the cast Hadfield steel caused a large increase of the tensile strength (37\%), strain-hardening exponent (50\%), elongation (53\%), toughness (88\%) and Charpy impact energy (13\%);

4. Microscopic examination of the fractured testpieces indicated that the austenite grain refinement of the cast Hadfield steel increased the density of mechanical twins (46\%);

5. The plastic deformation by twinning, which was promoted by the austenite grain refinement, played a significant role on the improvement of the mechanical properties of the cast Hadfield steel.

\section{References}

1. Hadfield's manganese steel. Science. 1888;12(306):284-286.

2. Tweedale G, Paton W. Sir Robert Abbott Hadfield F.R.S. (18581940) and the discovery of manganese steel. The Royal Society Journal of the History of Science.1985;40(1):63-74.

3. Giraldo AV. El acero Hadfield revisitado. Revista Colombiana de Materiales. 2012;3:1-24.

4. ASTM International. ASTM A128/A128M-93(2012) - Standard Specification for Steel Castings, Austenitic Manganese. West Conshohocken: ASTM International; 2012.

5. Tsujimoto N. Casting Practice of Abrasion Resistant Austenitic Manganese Steel. International Journal of Cast Metals Research. 1979;4(2):62-77.

6. Maratray F. High Carbon Manganese Austenitic Steels. Paris: International Manganese Institute; 1995.

7. Fuoco R, Todorov D, Cavalcanti AH, Santos NL. Effect of chemical composition on the carbide reprecipitation kinetics of Hadfield austenitic manganese steel. Transactions of the American Foundry Society. 2012;120:507-522.

8. Kuyucak S, Zavadil R, Newcombe P. On the heat-treatment of Hadfield's austenitic manganese steels Part I - VIII. AFS Special Report. Schaumburg: American Foundry Society; 2001.

9. Hall EO. The Deformation and Ageing of Mild Steel: III Discussion of Results. Proceedings of the Physical Society. Section B. 1951;64(9):747-753.

10. Petch NJ. The Cleavage Strength of Polycrystals. Journal of the Iron and Steel Institute. 1953;174(5):25-28.

11. Allain S, Chateau JP, Bouaziz O, Migot S, Guelton N. Correlations between the calculated stacking fault energy and the plasticity mechanisms in Fe-Mn-C alloys. Materials Science and Engineering: A. 2004;387-389:158-162.
12. Spindola MO, Dafé SSF, Carmo DJ, Santos DB. Microstructural characterization and mechanical behavior of a low-carbon 17 \% Mn sSteel. Materials Research. 2014;17(3):694-699.

13. Xiong R, Peng H, Wang S, Si H, Wen Y. Effect of stacking fault energy on work hardening behaviors in Fe-Mn-Si-C high manganese steels by varying silicon and carbon contents. Materials \& Design. 2015;85:707-714.

14. Curtze S, Kuokkala VT. Effects of temperature and strain rate on the tensile properties of twip steels. Matéria (Rio J). 2010;15(2):157-163.

15. Zhu TZ, Liao XZ, Wu XL, Narayan J. Grain size effect on deformation twinning and detwinning. Journal of Materials Science. 2013;48(13):4467-4475.

16. Dastur YN, Leslie WC. Mechanism of work hardening in Hadfield manganese steel. Metallurgical Transactions A. 1981;12(5):749-759.

17. Adler PH, Olson GB, Owen WS. Strain Hardening of Hadfield Manganese Steel. Metallurgical and Materials Transactions A. 1986;17(10):1725-1737.

18. Bayraktar E, Khalid FA, Levaillant C. Deformation and fracture behaviour of high manganese austenitic steel. Journal of Materials Processing Technology. 2004;147(2):145-154.

19. Yeleussizova AA, Skakov MK, Zhilkashinova AM, Rofman OV. Deformation Twinning in Hadfield Steel. Advanced Materials Research. 2013;772:62-67.

20. Haakonsen F. Optimizing of Strømhard austenitic manganese steel. [Thesis]. Trondheim: Norwegian University of Science and Technology; 2009.

21. Oguiza PC. Hadfield steel with Hf. European Patent. 2465 964 A1, 2012; 10.

22. Venturelli BN. Efeito do refino do tamanho de grão pela adição de Hf nas propriedades mecânicas de tração e impacto do aço Hadfield. [Dissertation]. São Paulo: Polytechnic School of University of São Paulo; 2018 (in Portuguese).

23. Kako K, Kawakami E, Ohta J, Mayuzumi M. Effect of Various Alloying Elements on Tensile Properties of High-Purity Fe18Cr-(14-16) Ni Alloys at Room Temperature. Materials Transactions. 2002;43(2):155-162.

24. Azevedo CRF, dos Santos AP. Environmental effects during fatigue testing: fractographic observation of commercially pure titanium plate for cranio-facial fixation. Engineering Failure Analysis. 2003;10(4):431-442.

25. Karaman I, Sehitoglu H, Beaudoin AJ, Chumlyakov YI, Maier HJ, Tomé CN. Modeling the deformation behavior of Hadfield steel single and polycrystals due to twinning and slip. Acta Materialia. 2000;48(9):2031-2047.

26. Qin B, Bhadeshia HKDH. Plastic strain due to twinning in austenitic TWIP steels. Materials Science and Technology. 2008;24(8):969-973. 